\title{
PERFORMATIVIDADES DE JOVENS DE ESCOLAS PÚBLICAS DE SP PELO OLHAR DE DOCUMENTÁRIO
}

\author{
PERFORMATIVITY OF YOUNG PEOPLE OF THE PUBLIC \\ SCHOOLS OF SÃO PAULO IN THE SCHOOL BY THE \\ DOCUMENTARY MOVIE LOOK
}

\author{
PERFORMATIVIDAD DE JÓVENES DE LAS ESCUELAS \\ PÚBLICAS DE SÃO PAULO POR LA MIRADA \\ PELÍCULA DOCUMENTAL
}

Samuel Pires Melo

${ }^{\text {I } U n i v e r s i d a d e ~ F e d e r a l ~ d o ~ D e l t a ~ d o ~ P a r n a i ́ b a ~(U F D p a r), ~ P a r n a i ́ b a / P I-B r a s i l ~}$

RESUMo Reconhecem-se aspectos educativos pelas performatividades de jovens em ações coletivas, muito embora continuam sendo produzidas narrativas controversas. Por isso, no presente artigo, faz-se um recorte a partir da película "acabou a paz, isto aqui vai virar o Chile! Escolas ocupadas em SP", dirigido por Carlos Pronzato, objetivando analisar a relação desse documentário com a capturação e produção de processos educativos a partir das narrativas de si de jovens estudantes nas ocupações das escolas públicas de São Paulo. Nessa produção, analisa, pela etnografia fílmica, falas e sequências que são mobilizadas com os conceitos de Juventude e educação (GROPPO, DAYRELL), performatividade da assembleia (BUTLER) e cinema de intervenção social (BRENEZ). Na significação dos sentidos dessa tecnologia, observou-se uma gramática de assembleias cuja linguagem se articula por meio da formulação de um discurso e de um entendimento público sobre os relatos de si produzidos nas redes educativas como denúncia, auto-organização, formação, diálogo e horizontalidade no cotidiano da mobilização social, relações de poder e subjetividades dos jovens. Portanto, a narrativa do documentário se faz em uma dimensão interventiva de corpos políticos produtores de aspectos educativos pela potência de engajamento, leituras do real e produção de memória de jovens estudantes de ocupações.

Palavras-chave: Movimentos Sociais; Associação de educaÇão; Filme documenTÁRIO. 
ABSTRACT Educational aspects are recognized due to the performance of young people in collective actions, even though controversial narratives continue to be produced. That is why, in this article, a cut is made from the film "peace is over, this is going to become Chile! Schools occupied in SP", directed by Carlos Pronzato, aiming to analyze the relationship of this documentary with the capture and production of educational processes based on the self-narratives of young students in public school occupations in São Paulo. In this production, he analyzes, through film ethnography, speeches and sequences that are mobilized with the concepts of Youth and education (GROPPO, DAYRELL), performativity of the assembly (BUTLER) and cinema of social intervention (BRENEZ). In the meanings of the meanings of this technology, he observed a grammar of assemblies whose language is articulated through the formulation of a discourse and a public understanding about the reports of himself produced in educational networks such as denunciation, selforganization, training, dialogue and horizontality in the social mobilization, power relations and subjectivities of young people. Therefore, the documentary narrative takes place in an interventionist dimension of political bodies that produce educational aspects due to the power of engagement, readings of the real and memory production of young students of occupations.

KeYWORdS: Youth MOVEMENTS; EduCATIONAL ASSOCIATIONS; DOCUMENTARY FILMS.

RESUMEN Los aspectos educativos son reconocidos por la actuación de los jóvenes en acciones colectivas, aunque continúan produciendo narrativas controvertidas. Por eso, en este artículo se hace un corte de la película "iSe acabó la paz, esto se va a convertir en Chile! Escuelas ocupadas en SP", dirigida por Carlos Pronzato, con el objetivo de analizar la relación de este documental con la captura y producción de procesos educativos a partir de las auto-narrativas de jóvenes estudiantes en ocupaciones de escuelas públicas en São Paulo. En esta producción analiza, a través de la etnografía cinematográfica, los discursos y secuencias que se movilizan con los conceptos de Juventud y educación (GROPPO, DAYRELL), performance del montaje (BUTLER) y cine de intervención social (BRENEZ). En los significados de los significados de esta tecnología, observó una gramática de ensamblajes cuyo lenguaje se articula a través de la formulación de un discurso y una comprensión pública sobre los informes de sí mismo producidos en redes educativas como la denuncia, la autoorganización, la formación, el diálogo y la horizontalidad movilización social, relaciones de poder y subjetividades de los jóvenes. Por tanto, la narrativa documental se desarrolla en una dimensión intervencionista de cuerpos políticos que producen aspectos educativos debido al poder de compromiso, lecturas de la producción real y de memoria de los jóvenes estudiantes de ocupaciones.

Palabras clave: Movimiento estudiantil; Asociación educativa; Documental.

\section{ENCONTRANDO DIÁLOGOS INTERAUTORAIS}

Compreendem-se a existência de corpos, linguagens e equipamentos brasileiros produtores de (des)ordem social, econômica, política e cultural. Tais produções são prota- 
gonizadas, entre outros grupos sociais, pelas juventudes que lutam por direitos a serem constituídos em atos, gestos, representações (BUTLER, 2003). Ou seja, mesmo diante da performatividade constituída temporalmente pelo gênero e corpo:

[...] atos, gestos e desejo produzem o efeito de um núcleo ou substância interna, mas o produzem na superfície do corpo, por meio do jogo de ausências significantes, que sugerem, mas nunca revelam, o princípio organizador da identidade como causa. Esses atos, gestos e atuações, entendidos em termos gerais, são performativos, no sentido de que a essência ou identidade que por outro lado pretendem expressar são fabricações manufaturadas e sustentadas por signos corpóreos e outros meios discursivos. $\mathrm{O}$ fato de o corpo gênero ser marcado pelo performativo sugere que ele não tem status ontológico separado (BUTLER, 2003, p. 194).

Isso significa que, apesar de princípios politicamente operativos da repetição, há uma política dos corpos possível da subversão pela performatividade que se encontra na torção dos arranjos dispostos, no entrecruzamento entre o "inteligível" e o estranhado, que podem desdobrar o poder na sua condição de repetição, produzida com certos grupos juvenis, como aquelas da participação sociopolítica e cultural em coletivos, movimentos sociais ou órgãos públicos (os Conselhos) que são, segundo Gohn (2018, p. 129), ações coletivas múltiplas e diversificadas, onde os grupos de jovens pertencem "a diferentes camadas sociais com ideologias e princípios filosóficos também diversificados, quando não opostos", por exemplo, os que se inspiram em ideias libertárias, mas "também o surgimento de organizações movimentalistas de jovens de perfil liberal ou conservador".

Sobre a pluralidade de princípios educativos produzidos nos coletivos de jovens, Gohn (2018) traz para o debate a tensão que essas diversidades de grupos pode estar provocando, principalmente porque "alguns adotam práticas democráticas e tentam pautar novos direitos sociais (passe livre, por exemplo); outros tencionam e enfraquecem a democracia, ao questionar direitos, como projetos do tipo 'Escola sem Partido' e outros".

As características apresentadas por Gohn (2018) sobre as diversidades de grupos juvenis e de suas produções educativas fazem parte do entendimento das juventudes enquanto categoria social constituída em suas subculturas. Isso porque, como salienta Groppo (2000), a juventude é definida como uma categoria social representando uma situação social e uma representação sociocultural pelas quais existem "[...] uma concepção, representação ou criação simbólica, fabricada pelos grupos sociais ou pelos próprios indivíduos tidos como jovens, para significar uma série de comportamentos e atitudes a ela atribuídos" (GROPPO, 2000, p. 8). Com relação a esses pontos de fruições, Butler e Spivak (2007) apontam uma reflexão interessante ao destacarem a manifestação de imigrantes ilegais na qual é cantado o hino estadunidense em espanhol - ato proibido no governo Georg W. Bush, em 2006:

Eu quero sugerir que este é precisamente o tipo de contradição performativa que leva não a um impasse, mas à forma de insurgência. Neste ponto não significa apenas situar a canção na rua, mas expor a rua como lugar de assembleia livre. Neste âmbito, a canção pode ser entendida não apenas como expressão da liberdade ou nostalgia de libertação - pensando, que é claramente ambas as coisas - mas também encenação na rua, representação da liberdade de livre 
assembleia precisamente quando e onde tal ato é explicitamente proibido pela lei. Isto é certamente política performativa, na qual realizar reivindicação para ser legalizado é precisamente o que é ilegal, e apesar disso é realizado precisamente em desafio da lei na qual o reconhecimento é demandado (BUTLER; SPIVAK, 2007, p. 63).

Sob essa perspectiva, compreende-se, assim como Dayrell (2007), a condição juvenil enquanto produtora de sentidos e identidades para além das performatividades delimitadas e normatizadas pela sociedade, reivindicando as contradições performativas aos seus modos de vida, apesar das contradições e impasses enfrentados. Em estudos realizados por Melo et al. $(2017,2018)$, observou-se que as juventudes estavam relacionadas às formas de insurgência, expondo assim seus corpos à liberdade de livre assembleia, revelando a complexidade das suas relações com os pares e com outros segmentos sociais.

Para esta discussão, delineia-se especificamente os coletivos juvenis que se mobilizam por meio de debates igualitários e soluções inovadoras para os desafios da juventude, adotando assim práticas democráticas com pautas em novos direitos sociais. Entre os últimos, destacam-se uma educação igualitária e inclusiva, com valores pautados na produção de todas as identidades de gênero, etnia, sexualidade, entre outros. Nesse cenário, Piolli et al. (2016, p. 24) apresentam uma caracterização dos coletivos secundaristas paulistas, compreendendo-os como:

[...] um movimento social autônomo porque possui as seguintes características: independência, horizontalidade, autogestão e utilização de táticas de desobediência civil e de ação direta. Os secundaristas que resistiram ao projeto do secretário da educação, Herman Voorwald, e do governador do Estado, Geraldo Alckmin, não são filiados a partidos políticos e não pertenciam a sindicatos ou organizações não-governamentais, nem recebiam financiamento de empresas ou de qualquer outra instituição. Muito embora tenham recebido apoio de membros e grupos ligados a partidos e às entidades estudantis, tais como a UBES.

Essas características produzem assembleias livres de ações coletivas juvenis com aspectos educativos que, para Groppo (2018), “[...] ajudam a dar forma e sentido a uma ação coletiva, talvez um movimento estudantil" (p. 88), provocado, de acordo com Groppo (2018), por duas ondas: a primeira, que ocorreu no período de dezembro de 2015 a junho de 2016 e teve seu campo de ação no âmbito dos Estados e pode ser localizada nos ciclos de protestos em oposição às políticas para a educação. A segunda onda ocorreu entre os meses de outubro e dezembro de 2016, tendo como marco inicial a oposição à Medida Provisória $n^{\circ}$. 746, de 2016 (MP 746/2016a), que propunha a reforma do Ensino Médio (BRASIL, 2016b) e o envio da Proposta de Emenda Constitucional no . 142, posterior PEC 55.

Levando em consideração a reação da primeira onda, é importante dizer que houve diversas ocupações nas escolas públicas do país. No caso de São Paulo, objeto do documentário analisado neste artigo, os jovens secundaristas promoveram um grande movimento de ocupação, em mais de 200 unidades escolares, durante cerca de 60 dias. Além das mudanças na educação propostas em âmbito nacional, as ocupações de São Paulo ocorreram principalmente por conta da proposta de reorganização escolar, em que se pretendia dois pontos fundamentais: 
1. Preparar a rede estadual para um segundo movimento de municipalização do ensino com transferência do ensino fundamental para os municípios, intensificando o processo de transferência de matrículas que vem ocorrendo desde a promulgação da LDB [...] e; 2. Preparação da rede para um movimento de publicização e privatização do ensino médio tal como já vem ocorrendo em Goiás, Pará e Pernambuco, isso tanto nas escolas em tempo integral como também na proposta de flexibilização curricular (PL 1.083/2015).

A compreensão desse projeto de lei pelos jovens ocupantes das escolas, como um risco à permanência da educação pública, produziu uma resistência que transbordou em outros temas relacionados às escolas públicas no Estado. Esses coletivos foram ampliando suas pautas com denúncias referentes à falta de relações democráticas na escola, à precariedade das escolas (pela falta de professores, infraestrutura e gerenciamento) e os debates de temas como: relações de gênero, racismo e homofobia, entre outros (PIOLLI et al., 2016).

É importante dizer que antes da narração em si dessas manifestações, segundo Butler (2018), os encontros coletivos transbordaram o que na superfície significava, e esse modo de significação pressupõe uma incorporação da ação, uma performatividade plural:

Como, então, pensamos essas reuniões transitórias e críticas? Um argumento importante que se segue é que importa que os corpos se reúnam em assembleia e que os significados políticos transmitidos pelas manifestações sejam não apenas aqueles transmitidos pelo discurso, seja ele escrito ou falado. Ações corporificadas de diversos tipos significam, de forma que não são, estritamente falando, nem discursivas nem pré-discursivas. Em outras palavras, as formas de assembleia já têm significado antes e apesar de qualquer reivindicação particular que façam. [...] Podemos ficar tentados, com base em velhos hábitos, a dizer: "mas se algo significa, então é certamente discursivo", e talvez isso seja verdade. Mas essa réplica, mesmo que se sustente, não nos permite examinar a importante relação quiasmática entre as formas de performatividade linguística e as formas de performatividade corpórea. Elas se sobrepõem; elas não são completamente distintas, elas não são, no entanto, idênticas uma a outra (BUTLER, 2018, p. 13-15).

A abertura para a contingência na performatividade cria o leque de entendimento em Butler (2018) para a ação. Nela, a questão não é ter poder e então ser capaz de agir, mas agir e nessa ação conquistar a força que se necessita para lutar. O poder não está necessariamente no espaço ou no corpo, mas na atividade articulada com o espaço, com os corpos e com o real, no agenciamento produtor da política.

As ocupações das escolas pelos corpos em ação operaram como mecanismos de produção desses espaços da política que antes não estavam constituídos como tais ou eram ocupados por mecanismos de normatização e policiamento escolar, mas a "[...] ousadia e a coragem dos jovens alargaram o horizonte do possível, mostrando que a escola, como a própria vida, pode sempre ser reinventada" (CORTI; CORRACHANO; ALVES, 2018, p. 138).

Ao pensar a performatividade de manifestações pela sua pluralidade, Butler (2018) alarga o conceito de espaço público como relacional, unido por pessoas. Logo, a rua não é pública de cara, é um equipamento que é usado pelos corpos, mas não acontece só entre os 
corpos, como também pelos equipamentos que são produzidos e renovados, reconfigurando os sentidos da rua e também suas posições de aparição. Por isso:

\begin{abstract}
Um primeiro elemento de destaque nas ocupações é a capacidade de auto-organização dos estudantes [...]. Formam comissões e organizam a limpeza, a conservação, a vigilância, as atividades políticas e formativas. Constroem regras e tomam decisões a partir de assembleias soberanas. [...] Em segundo lugar, em tal formação política, rompem-se as barreiras entre as funções tradicionais dos agentes educacionais (professores versus estudantes), os limites e os papéis das categorias etárias (jovens guiados por adultos) e, enfim, as fronteiras entre o público e o privado. [...] Em terceiro lugar, trata-se de uma formação política que nega a ideia de que é preciso primeiro se "qualificar" ou se "habilitar" com valores e atitudes fundamentais, antes de poder agir politicamente e apresentar-se ao mundo público. Ao contrário, concebe-se que o jovem já é um ser político, capaz de agir publicamente e promover mudanças relevantes na ordem social desde seu ponto de vista a respeito dos assuntos públicos (GROPPO et al., 2017, p. 145-148).
\end{abstract}

No sentido de reorganizar os argumentos levantados por Groppo et al. (2017), Piolli et al. (2016), Corti; Corrachano; Alves (2018), este artigo amplia a discussão destacando, por meio da performatividade da assembleia de Butler (2018), a denúncia como efeito das cenas e aparições produzidas no documentário "Acabou a paz, isso aqui vai virar o Chile! Escolas ocupadas em SP”. A denúncia é produzida pelo movimento de política corporal, principalmente pela importância das narrativas de si que conectam os corpos, na performatividade que não é somente a produção de uma pessoa, mas também como algo encenado no coletivo da ocupação das escolas, produção do documentário e a memória dos presentes. Afinal, as lutas por liberdades individuais se conectam no que se tem pensado como lugares de corpos atuantes e de corpos movendo-se livremente dentro de uma democracia.

Observa-se, com isso, que os estudantes exploraram os corpos de si, e com isso romperam as normas em ato do administrativo, técnico e numérico, produzindo um modo de coexistir por corpos relacionais que podem suspender essas normas, mesmo que provisoriamente, reorganizando aspectos educativos em seus movimentar-se socialmente (BUTLER, 2018).

Os estudantes deixaram de ser, ainda que provisoriamente, um sujeito abstrato e universal e uma categoria administrativa e escolar para ocupar a posição de sujeito com voz e corpo próprios. Nos discursos de poder, estes estudantes aparecem como culpados ou como vítimas: culpados pelos comportamentos indisciplinados, violentos ou simplesmente apáticos e desinteressados no interior da escola ou vítimas passivas de um sistema de ensino precarizado que os mantém mergulhados na ignorância, na exclusão social e na impotência (CROCHIK; CORTI, 2018, p. 5).

$\mathrm{Na}$ verdade, essas performatividades em assembleia dos jovens estudantes produziram aspectos educativos por meio de fraturas nos discursos institucionalizados. Eles conseguiram construir outra existência corporificada e visível. Por sua vez, questiona-se em que medida um filme documentário pode capturar essas experiências insurgentes, produzindo processos educativos a partir da realidade das ocupações das escolas públicas de São Paulo. 
Ao trazer para a frente da discussão a narrativa do documentário, compreende-se nele um gênero que está no centro dos debates políticos do cinema, utilizando-se de uma estética política na narrativa militante. Como afirma Brenez, " [...] o cinema de intervenção existe apenas na medida em que levanta questões cinematográficas fundamentais: por que fazer uma imagem, que imagem e como? Com quem e para quem? Contra que outras imagens ela se confronta? Por que? Ou, posto de outro jeito, que história queremos?" (BRENEZ, 2013 , p. 5 e 6). Isso porque, nessas imagens, constroem-se uma estética sensível ao impacto e implicados nos gestos de sublevarem-se perante as injustiças com as quais se deparam.

O fenômeno da imagem, do pensamento em imagem, do espírito que pensa por meio de imagens, é um problema que deve ser considerado como de outra natureza que a simples enumeração, a simples análise da imagem que é um meio, que é a análise técnica e não aquela de um fenômeno intelectual ou de um fenômeno cuja base se liga ao mecanismo da percepção. Temos aqui uma noção verdadeiramente importante e que é absolutamente fundamental. [...] Ela [a imagem] existe em si, ela existe essencialmente no espírito, ela é uma referência na cultura e não uma referência na realidade (BAZIN, 1985, p. 193).

Pensa-se, nesse sentido, a estética das imagens do documentário “Acabou a paz, isso aqui vai virar o Chile! Escolas ocupadas em SP" em seus aspectos educativos, principalmente porque, como salienta Didi-Huberman (2017), as imagens são vistas como "objetos de gestos" (transmitem afetos) e "objetos de ação" (estabelecem táticas e técnicas). Em um trabalho de curadoria, esse autor argumenta que os levantes:

[...] surgem dos psiquismos humanos como gestos: formas corporais. Sem dúvida alguma, são forças que nos sublevam, mas são formas que, antropologicamente falando, tornam perceptíveis, veiculam, orientam, implementam os levantes, tornando-os plásticos ou resistentes de acordo com as circunstâncias [...] O que nos torna protagonistas de um levante? Vamos partir da hipótese de que é a força de nossas memórias quando se inflamam junto às memórias de nossos desejos - imagens que se encarregam de inflamar nossos desejos a partir das nossas memórias, memórias no vazio de nossos desejos (DIDI-HUBERMAN, 2017, p. 296-301).

Mais do que simplesmente serem consideradas imagens paradas ou em movimento (com som) capaz de entreter o espectador, essas são produtoras/potências para os desejos, no caso deste artigo, para uma dimensão interventiva da imagem política produtora de aspectos educativos. Isso porque:

A principal aposta do cinema engajado é na sua eficácia histórica, e isso ocorre em relação a três pontos, dos quais cada filme organiza a sobreimpressão, segundo os imperativos do combate. [...] No fogo da ação, René Vautier definiu como "cinema de intervenção social" um trabalho de instantaneidade performativa que visa o sucesso de uma luta e a transformação concreta de uma situação de conflito declarado ou de injustiça estrutural. [...] Em médio prazo, o trabalho consiste em difundir uma contrainformação e agitar as energias. [...] A longo prazo, tratou-se de filmar, e assim conservar fatos para a história, constituir do- 
cumentos, legar um arquivo e transmitir a memória das lutas às gerações futuras (BRENEZ, 2017, p. 71).

Esses pontos destacados por Brenez (2017) sobre o cinema de intervenção são importantes para pensar os aspectos educativos do documentário aqui analisado principalmente porque os gestos/ações de que tratam as imagens do documentário produziram uma intervenção no passado, mas também como (contra)informação e de legado de um arquivo, uma memória para a luta no presente ou futuro próximo.

Se a imaginação - esse mecanismo produtor de imagens para o pensamento

- nos mostra o modo pelo qual o Outrora encontra, aí, o nosso Agora para se liberarem constelações ricas de Futuro, então podemos compreender a que ponto esse encontro dos tempos é decisivo, essa colisão de um presente ativo com o seu passado reminiscente (DIDI-HUBERMAN, 2011, p. 61).

Compreende-se, nesse sentido, que o documentário pode se abrir para levantes porque está em permanente conexão com corpos e equipamentos em temporalidades diversas. Por exemplo, o filme que reconhece um presente situado pelo passado, com perspectiva para o futuro, principalmente por conta das formas de agir/ação que determinarão outro caminho da história, uma vez que terão produzido imagens para uma memória do presente que pode inflamar "a memória dos nossos desejos".

\section{SENTIDOS PARA PRODUÇÃo do CAMINHO METODOLÓGICO}

Ao analisar que o fenômeno estudado se dá pela compreensão das subjetividades de códigos simbólicos, observa-se na etnografia fílmica uma abordagem fundamental, principalmente porque com ela é possível ir além da tela e ao encontro das possibilidades de usos do audiovisual. Com essa abordagem de pesquisa, é possível interrogar filmes por se tratarem de documentos culturais que projetam imagens do comportamento social humano (WEAKLAND, 1995). Nessa perspectiva, Canevacci (1990, p. 29) explica a necessidade da análise antropológica do cinema como:

[...] subcultura interna ao sistema das novas tecnologias - tem necessidade de reflexões globais e radicais para responder às perguntas sobre sua relação entre máquina-cinema e as modificadas categorias centrais da humanidade: o tempo, o espaço, o rito, a fábula, a vida, o riso, o comportamento na sala, o trabalho, o corpo, a morte, as classes sociais. E, por isso, uma nova tentativa de compreensão do cinema pode ser colocada no plano antropológico.

Compreende-se, portanto, o caráter investigativo do filme/documentário, particularmente pelo processo de descrevê-lo e interpretá-lo (PENAFRIA, 2009), como a um texto, no sentido atribuído por Geertz (2008). Ao descrevê-lo e interpretá-lo pela linguagem etnográfica, atenta-se para a condução do olhar rumo a pormenores e minúcias do documentário, por uma observação participante atenta ao cotidiano alheio. Nesse caso, por meio de 
questionamentos sobre "quem fala? De onde fala? Quais são as principais categorias postas em movimento e como se dá o agenciamento destas categorias? De que maneira determinados agentes de discurso e suas posições foram construídas? Que estratégias são acessadas para se garantir a circulação dos discursos? Como se dá o processo de negociação entre os agentes para a produção de consenso? "O objectivo da Análise é, então, o de explicar/esclarecer o funcionamento de um determinado filme e propor-lhe uma interpretação. Trata-se de fazer uma reconstrução" (PENAFRIA, 2009, p. 1-2). Na verdade:

As análises que aqui se propõem consideram os filmes - um a um ou por grupos em sua globalidade - como práticas significantes; elas estudarão neles seus mecanismos, mas colocar-se-ão a tarefa de jamais isolar seu funcionamento da configuração ideológica ou do meio social nos quais se inserem. [...] É certo que a recepção do filme pelos espectadores passa por ajustamentos automáticos: o público fica tanto mais satisfeito quanto menos problemas ele tem em situar o que vê em referências que lhe são familiares. Mas nosso trabalho consiste precisamente em recusar o que é exterior ao filme e reter apenas as indicações presentes na tela (SORLIN, 1977, p. 58, 174).

Com essa perspectiva, pôs-se a dialogar com os informantes constituintes do documentário, onde foi visto inúmeras vezes, ora registrando impressões e leituras diversas, ora apenas as cenas com as falas dos participantes, com seus desdobramentos, técnicas corporais, enquadramentos, planos e demais itens da montagem do filme. Na verdade, a descrição e a interpretação seguiram os passos propostos por Penafria (2009, p. 1-2), principalmente:

i) Informações [...] ii) Dinâmica da narrativa. Fazer a decomposição do filme por partes (sequências e/ou por cenas) [...] iii) Pontos de vistas. A expressão "ponto de vista" pode ser trabalhada em três sentidos: 1 - Sentido visual/sonoro (onde está a câmara em relação ao objecto a filmar? Que sons podem ser ouvidos ao longo do filme e em que momentos? Quais as características dos planos? [...] 2 - Sentido narrativo (Quem conta a história? E como é contada?). [...] 3 - Sentido ideológico. Aqui pretende-se verificar qual a posição/ideologia/ mensagem do filme/realizador em relação ao tema(s) do filme. [...] v) Conclusões. Por forma a interpretar o valor cinematográfico de um determinado filme.

Nesse delineamento, o artigo leva em consideração, com maior ênfase, pelo menos quatro dos cinco aspectos propostos por Penafria (2009), principalmente diante dos questionamentos gerais desse ensaio: em que medida filmes documentários podem ser capturadores e produtores de processos educativos? E mais, como esses olhares no documentário são continuamente desdobrados em performatividades de assembleia dos jovens estudantes nas ocupações das escolas públicas de São Paulo.

\section{"Eles ReSOLVERAM OCUPAR AS ESCOLAS PARA SE EMPODERAR DISSO"}

A narrativa de 60 minutos do documentário "Acabou a paz, isso aqui vai virar o Chile! Escolas ocupadas em SP”, produziu tecnologias nos mais diversos sentidos dessa 
linguagem em jovens ocupantes das escolas públicas de São Paulo. Essa produção audiovisual foi lançada depois de dois meses da vitória dos estudantes secundaristas sobre a reorganização escolar. Ela descreve o que muitos desses jovens estudantes ocupantes construíram entre novembro e dezembro de 2015.

Produzido, dirigido e montado por Carlos Pronzato, que utilizando de discursos de sujeitos participantes do levante (alunos, professores, representantes de sindicato, movimentos sociais, organizações civis, coletivos e pais etc.), buscou representar uma visão ampla de um coletivo de dentro para fora. Teve ainda apoio, na montagem da obra, de imagens dos atos, repercussão na mídia do que ocorreu e como isso se desenvolveu até o anúncio da suspensão da reorganização, bem como, de clipes de músicas sobre o assunto e cenas de documentário anterior (Rebelião dos Pinguins) produzido por Pronzato.

É importante destacar que o lançamento dessa obra audiovisual foi preciso no tempo, pois como a proposta de reorganização escolar estava ocorrendo a portas fechadas e às escondidas pelo governo Estadual, ela veio para aumentar a visibilidade dos fatos que estavam chegando. A sutileza do diretor, abrindo espaço principal aos alunos, é um claro sinal que ele entendeu o que foi o coletivo, feito por alunos e a construção natural e horizontalizada da noção de um bem público (a Escola), como algo a ser construído por todos, de forma democrática.

Observa-se, a cada entrevista, uma relação sócio-histórica com acontecimentos anteriores, seja na América Latina (Coletivo estudantil no Chile, 2006) ou no Brasil, com as manifestações de junho de 2013. Esses fatos inspiram lutas por direitos e contra um Estado que não satisfaz as necessidades de grupos sociais. Além disso, o papel fundamental dos que apoiaram a causa no período de ocupação dos prédios, especificamente os partidos de esquerda, coletivos, sindicatos, comunidade e os pais dos alunos.

Ao destacar nos discursos dos entrevistados a rotina de cuidados e organização, Pronzato conduz o espectador ao entendimento de movimentos de política corporal que esses jovens ocupantes foram construindo. O quanto eles cresceram com o protagonismo das escolas ocupadas, por meio da atenção ao espaço com a limpeza em dia, revezamento de funções e uma horizontalidade que não se vê em outros campos. Salienta-se ainda que o ritmo do documentário é sutil porque vai encadeando cenas das ações produzidas pelos corpos e tecnologias, mas também pelo recorte das falas dos protagonistas como denúncia.

Portanto, este texto destaca as linhas de força de um filme/documentário na reintrodução de aspectos educativos no cotidiano da mobilização social, relações de poder e subjetividades dos corpos juvenis. Com o intuito de compreender como são produzidas essas linhas, destacam-se os tópicos: "o espaço do reconhecimento da ocupação estudantil pela tecnologia do documentário" e "a narrativa de si que produz uma performatividade sob movimentos de política corporal para a denúncia, auto-organização, formação, diálogo e horizontalidade".

\section{EM CENA UM: O ESPAÇO DO RECONHECIMENTO DA OCUPAÇÃO ESTUDANTIL PELA TECNOLOGIA DO DOCUMENTÁRIO}

\footnotetext{
"os estudantes da rede pública estadual estão lutando desde o dia 06 de outubro contra a reorganização escolar proposta pelo governo do Estado de São Paulo. Mesmo com diversas manifestações que pararam a cidade, cobrando da secreta-
} 
ria de educação e diretoria de ensino de todo o estado, nós não fomos ouvidos, e por isso decidimos ocupar as escolas" (Eudes, estudante da escola estadual Fernão Dias).

Esse é um trecho da carta lida por um jovem em uma reunião da ocupação de uma escola de São Paulo, e que faz parte da primeira cena do documentário "Acabou a paz, isso aqui vai virar o Chile! Escolas ocupadas em SP". Ainda nessa cena, diga-se produzido em plano aberto, observa-se um número significativo de jovens sentados em um pátio de uma escola pública, ouvindo a leitura da carta escrita pelo coletivo, percebe-se no trecho lido que trata da deflagração da ocupação. Em seguida, entra em cena o clipe da música "Ocupar e Resistir", Letra: Koka e Fabricio Ramos, cantada por Koka. O cantor enfatiza que os secundaristas estão em performatividade da assembleia buscando espaço de reconhecimento sobre o descaso das instituições políticas para com a educação e ao mesmo tempo reivindicar uma educação formal. É importante dizer que durante toda a narrativa do documentário os ocupantes anunciam relatos de si, de forma a produzir o protagonismo juvenil de coletivos.

Sobre o interesse por esse grupo social, em uma reportagem concedida ao site Diário do Centro do Mundo, o produtor desse longa-metragem, Carlos Pronzato (2016) explica que o motivo de realizá-lo estava relacionado ao percurso que vinha fazendo com o tema estudantil havia alguns anos, ele fala especificamente da Revolta do Buzu, em Salvador (2003), que impulsionou a criação do Movimento Passe Livre, e também, em 2006, quando da produção do documentário "Rebelião dos Pinguins" (que aborda o início e desenvolvimento de ocupações em escolas secundaristas no Chile contra o sistema vigente, em busca da melhoria das condições de educação em todos os níveis no país). Segundo a denúncia de um jovem e uma jovem manifestante, a tecnologia desse documentário foi importante para os corpos políticos produzirem as ocupações, já que:

"[...] descobriram um documentário da revolta dos pinguins, e aí baseado no documentário que elas assistiram, disseram: olha, até que a ideia é viável, né? $\mathrm{Na}$ brincadeira assim, pode ser uma coisa mais" [mesclando com a fala do aluno são apresentadas imagens sobre o documentário a revolta dos pinguins, bem como reportagens sobre o levante que aconteceu no Chile]" (Douglas, estudante da Escola Estadual Diadema).

"e aí a gente olhou uma na cara da outra, as meninas disseram: a gente só vai saber se tentar [...] aí a gente chamou o pessoal numa assembleia e falou: galera o que vocês acham de ocupar a escola? E distribuímos a cartilha [como ocupar um colégio]" (Rafaela, estudante da Escola Estadual Diadema).

As cenas em que esses estudantes denunciam os elementos da mobilização trazem um entusiasmo sobre o levante dos jovens estudantes do Chile, principalmente pelo resgate da memória de luta daqueles estudantes por direitos. Nessa linha, Pronzato (2016) salienta que o documentário "Rebelião dos pinguins" foi muito utilizado pelos jovens nas ocupações das escolas de São Paulo, assim como uma cartilha feita pelos estudantes chilenos para as ocupações. Por essa perspectiva, observa-se no filme/documentário:

Tomadas na sua urgência e função (informar, mobilizar, comover, disputar sen- 
tidos) essas imagens atravessam diferentes fronteiras e tiram sua força do dorso do presente, mas trazem no seu interior potências e estéticas virtuais, nessas dramaturgias do grito. [...] São imagens que carregam a marca de quem afeta e é afetado de forma violenta, colocando o corpo/câmera em cena e em ato. A sobrevivência das imagens e sua captação está diretamente colada à sobrevivência de um corpo, de um animal-cinético, que filma enquanto combate e foge, enfrenta inimigos (BENTES, 2014, p. 335).

Acontece nesse processo uma dimensão educativa da estética enquanto dispositivo político que não passa apenas pela ordem do que é dito (jovens ocupantes das escolas de São Paulo espectadores do documentário "Rebelião dos Pinguins"), mas do que é pressuposto e que indicam diferentes níveis de divisões entre os que acionam a tecnologia do filme/documentário para tomarem parte na ordem do discurso político direta e indiretamente, experimentando a partir de suas realidades, os vários momentos que confluíram com a ocupação e a produção do documentário. Na verdade:

No cinema de Carlos Pronzato, além destas ligações histórico-temporais, as conexões estabelecidas por ele e seus filmes são perpassadas por diferentes transversalidades, como por exemplo, as que se dão dentro do espaço geográfico latino-americano [...] A reapropriação da rebelião pinguina por parte dos jovens paulistas entre 2015 e 2016 está bem caracterizada no título de outro documentário [...] A provável inspiração para o título veio de um canto (palavra de ordem) bravejado pelos estudantes durante a luta contra a reorganização, algo possível de ser visto em trecho do filme. A frase "Isso aqui vai virar o Chile" (BARCELOS, 2017, p. 8-10).

Pode-se dizer que os aspectos educativos desse documentário de Pronzato se constituem no próprio ato de experimentar a mobilização (ligado à forma como a imagem produz atrito aos sujeitos e como esses produzirão o lugar da ocupação/manifestação). Há de se salientar ainda nesse documentário que não são apenas as imagens constituintes do caminho político, mas também a presença dos corpos e suas produções com essas imagens, desde a leitura delas, operacionalização da câmera ao processo de edição.

"essa é a nossa arma, nossa ferramenta de defesa contra agressões, e eu estava
falando justamente isso pros estudantes. Vocês têm celulares? Temos, então va-
mos aprender a usar o celular para gravar. E quando dava oficina para aprender
a gravar um vídeo, com o celular, a gente já fazia um vídeo para veicular. Então
a oficina já era produção do vídeo. Vamos fazer uma encenação de como um po-
licial aborda, e como a gente pode gravar? Vamos, aí fizemos um vídeo chama-
do dicas para gravar. Através desse vídeo todo mundo aprendeu a usar o celular
para gravar e se defender das abordagens" (Lucas, Educador e Vídeorrepórter).

As cenas, em planos abertos e fechados, que exemplificam como os estudantes devem agir em uma abordagem policial, procuram mostrar a proposição dos sujeitos que $f a z e m f a-$ zer com a câmera, é um cinema militante que está engajado na luta pelo direito à educação. Pronzato, nesse documentário, não está preocupado em apresentar um cenário de lamentações, mas a mobilização realizada para o reconhecimento do estado de precarização dos 
espaços escolarizados. A linguagem construída no documentário permite situar os gestos dos diversos atores na disputa por sentidos que se abrem para uma dimensão simbólica do fazer "[...] filmes que originem filmes" (GRANJA, 1981, p. 182).

É possível observar, nesse sentido, que a linguagem do documentário abre diversas cenas com os coletivos de estudantes produzindo ações democráticas. Seja por meio da criação/reconfiguração de aspectos contínuos na manutenção dos atos das manifestações, ou por intermédio da construção do lugar nas ocupações dos espaços escolares. Com essas ações, os estudantes ganharam visibilidade articulando-se por meio de uma estratégia sociopolítica de denúncia sobre a auto-organização do cotidiano e propagada principalmente para a mídia independente, em coprodução com eles.

\begin{abstract}
"as assembleias são também democráticas. Assim, acho que todo mundo fala, todo mundo expressa opiniões, todo mundo dá palpite, fazem propostas, assim todo mundo debate sobre tudo. Tanto à organização interna aqui da ocupação, quanto o que está acontecendo externamente, nas mídias, em atos, e o que as pessoas têm comentado sobre o pessoal da ocupação" (estudante Thainá, da escola Fernão Dias).
\end{abstract}

É importante dizer que o documentário destacou a democratização da participação das mulheres em toda a narrativa do processo de ocupação das escolas, principalmente por meio de uma linguagem performativa na qual se pratica, se pensa e, por conseguinte, se constrói o gênero pela reação à captura do espaço escolar para o capital e à opressão articulada pelas desigualdades educacionais, mas também pela emergência de uma reflexão sobre as estruturas tradicionais do campo da esquerda e das lutas por direitos. Por sua vez, não se deve pressupor com isso um roteiro estabelecido, o interior desses coletivos é alimentado por um complexo rizoma de subjetividades (BUTLER, 2018).

\title{
EM CENA DOIS: A NARRAÇÃo DE SI QUE PRODUZ UMA PERFORMATIVIDAdE SOB MOVIMENTOS DE POLÍTICA CORPORAL PARA A DENÚNCIA, AUTO-ORGA- NIZAÇÃO, FORMAÇÃo, DIÁLOGO E HORIZONTALIDADE
}

\footnotetext{
“Tinha muita gente que antes de 2013 não tinha tomado gás, nunca tinha ido para uma manifestação, e muita gente, sei lá... foi se acostumando mesmo, inclusive o que está acontecendo agora, muito estudante, a imensa maioria, nunca tinha tomado gás, e agora está tomando, mas acho que a gente conseguiu em 2013 mudar um pouco o que era uma manifestação de rua, né? Que é a polícia tacar a bomba e a gente tacar de volta... não fugir, acho que a gente tirou de acúmulo foi isso, tentar não temer a polícia, né? Que foi uma coisa que em 2013 a gente conseguiu, a polícia tacou e a gente dava mais forte" (Chico, escola estadual Fernão Dias).
}

A narrativa de si do estudante Chico é categorizada pela denúncia que emerge como unidade operadora de sentidos da cena, constituindo-se numa fala que reúne um conjunto de marcações que se tornam significativas no contexto da assembleia dos corpos políticos das ocupações ocorridas em São Paulo, principalmente porque esse relato de si é signifi- 
cado no documentário pelas imagens de manifestação de rua configuradas pelo trânsito com carros de passeio, motocicletas e ônibus parados, movimento da polícia para atacar os manifestantes e a reação destes, munição mostrada pelas mãos dos manifestantes, conflito entre polícia e corpos políticos. Após essa cena, aparece o estudante Chico, em plano médio aberto, com destaque para o cenário composto por mochilas, roupas dos ocupantes e mais no fundo quadros com desenhos de guitarras. Há de observar, portanto, que esse conjunto ocorre na medida em que denúncias são vistas como efeitos das cenas e aparições, em situações de assembleia.

Importa dizer também que a categoria denúncia vai sendo circunscrita, de certa forma, com outras categorias, por exemplo, horizontalidade, isto porque os efeitos das cenas remetem a aparições significadas pela horizontalidade:

"aqui todos horizontais, onde os alunos têm poder de falar, ou seja, não há uma liderança! Só que quando nasci eu não vi uma luta desse tamanho, e segundo historiadores, políticos, uma luta desse tamanho é agora. São os estudantes que estão fazendo, são 171 escolas ocupadas" (estudante sem identificação, de uma escola ocupada).

Essa narrativa apresentada pelo aluno em plano mais fechado, com uma cena em que vários jovens se encontram por detrás das grades do portão da escola, destaca a horizontalidade em uma aliança com a categoria autogestão (GROPPO, et al., 2017), principalmente por conta de um processo educativo em que se verifica no documentário narrações de si (desses jovens) para que se compreendam as ocupações em sua autogestão. A correlação entre os termos autogestão e auto-organização diz respeito, segundo Groppo et al. (2017), às atividades do cotidiano, onde prevaleçam a participação dos sujeitos por todas suas práticas sociais. E é justamente isso que vai permear a narrativa do documentário, inclusive no que diz respeito à ligação partidária.

"assim eles estão contribuindo para a luta, não são lideranças da luta, a luta
está sendo autônoma mesmo, a gente vê outra ligação [quer dizer, inspiração]
como a partir do "mal educado", que fez o panfleto de como ocupar uma escola,
que acho que foi o que impulsionou mais a um processo de ocupação. Assim,
foi quem impulsionou o coletivo do grupo, quem impulsionou as ocupações
[cartilha mal educado]. E aí os outros estavam lá contribuindo como puderam,
tal, mas a luta mesmo está sendo autônoma, não tem ligação partidária, tem os
partidos que apoiam, mas apoiam a luta dos estudantes" (Chico, estudante da
Escola Estadual Fernão Dias).

Quando se remete à fala do estudante Chico sobre o protagonismo da ocupação estudantil, a narrativa do documentário traz para a experiência uma linguagem tecnológica que precisa dar conta de uma assembleia que emerge como uma unidade gestora de sentidos da cena, operando sob duas temporalidades, a da própria narrativa, pois ao fazer a narração de si o jovem produz uma afirmação de autonomia do coletivo, mas também o reconhecimento da cooperação como importante para a manutenção da autogestão, numa autonomia participativa. "Os movimentos autônomos criticam e se diferenciam dos movimentos tradi- 
cionais, especialmente, em um aspecto, qual seja, a distribuição de poder entre os membros do movimento" (PIOLLI et al., 2016, p. 24).

É interessante perceber que a narrativa do documentário dialoga com as análises feitas por Piolli et al. (2016), no que diz respeito à inovação na forma de produção dos coletivos estudantis de São Paulo, que se dá justamente diante das demandas dos sujeitos sociais contemporâneos preocupados em uma mudança que não está em apenas institucionalizar os sujeitos dentro de uma causa. Por sua vez, ultrapassa-se Piolli et al. (2016) quando se percebe um faz fazer entre as narrativas de si e o filme/documentário (tecnologias produtoras de formas organizacionais) que possibilitam uma maior liberdade na manutenção das diversas maneiras de produção das assembleias. Isso pode ser observado na narrativa de uma aluna:

\footnotetext{
"eu comecei na ocupação vindo para aula em um dia normal. E aí estava tudo parado, cheio de polícia e eu não entendendo nada, nem imaginava da ocupação, não sabia sobre a reorganização ainda, e fiquei vendo como é a rotina de todo mundo aqui na ocupação. Aí peguei mais ou menos num dia, no outro, aí peguei mais um pouco do pessoal, aí quando eu vi, já estava engajada, era porta-voz, responsável por falar com a mídia, com jornalista" (Thainá, estudante da Escola Estadual Fernão Dias).
}

A performance narrativa no relato de si da Thainá põe em evidência aspectos interessantes na forma como os corpos se fazem nos espaços de assembleia, por exemplo, pela interação entre integrantes dos coletivos e simpatizantes, sobressaindo a liberdade na participação, ou mesmo a lida com a tecnologia do filme/documentário. Essa película produz saberes em sua narrativa que atravessam um faz fazer democrático ligado ao princípio da ação, que visa o combate a uma hierarquia do poder institucionalizado (em que estudantes aparecem como culpados ou como vítimas).

Busca evidenciar, no entanto, a abertura das possibilidades pela ocupação da posição de sujeitos com voz e corpo próprios, mas que construíram um senso de organização e de conscientização durante o processo de manifestação e ocupação que produziram pautas mais complexas do que a reorganização escolar proposta pelo governo do Estado de São Paulo.

\footnotetext{
"eu vi nascer uma coisa dentro da escola que eu realmente acho que todas as escolas do mundo tinham que passar por um processo de ocupação, porque os meninos, eles se empoderaram de tal maneira, e eles discutem seus direitos e o processo que é negado a eles como eu nunca vi”' (Viviane D'Almeida, Comitê das mães e pais de luta).

“essa luta, não tenho dúvida nenhuma, ela daqui a dez anos a gente vai estar falando sobre ela, porque ela marcou uma geração, e marcou uma juventude que certamente não vai parar aí na luta pela democracia pelos direitos sociais e tal. Esses caras que surgiram, eles querem mais, tenho certeza que eles vão protagonizar outras tantas lutas que vão fazer [...] do Brasil um país melhor" (Laura, Jornalista livre).
}

Essas falas no documentário trazem narrativas de si que confluem para a legitimação das ações desses estudantes. Eles exaltam a maneira que esses jovens se dedicaram ao 
processo de ocupação. Tem relevância a articulação entre os membros e os apoiadores para fazer que todos os espaços fossem ocupados com ações que levassem a uma produção de sentidos não somente do lugar da reorganização escolar no modo de vida das pessoas envolvidas, mas de como melhorar o cotidiano de uma sociedade marcada pelas desigualdades. "Daí a possibilidade dos diálogos entre as gerações e o aprendizado recíproco entre suas experiências, construídas a partir de diferentes modos de estar no mundo e vivenciar o tempo" (GROPPO et al., 2017, p. 149).

O reconhecimento da autonomia das ocupações e de suas formas de apoio coloca em evidência no documentário aspectos educativos dos coletivos sociais que levam em consideração as denúncias nas narrações de si que dão sentido de intervenção partilhada. Desde a observação da complexidade do acontecimento à ação sobre esse acontecimento e suas múltiplas conexões sociopolíticas e culturais.

\footnotetext{
"Uma moça veio ontem do Rio de Janeiro para dar uma palestra sobre maioridade penal, a gente já teve três palestras sobre maioridade penal. É muito? Não, é pouco. A gente já teve quatro sobre violência contra a mulher e feminismo. É muito? Não, é pouco. Mas esse é o grande medo dele lá, a gente está recebendo informação aqui” (Manuela, estudante da Escola Estadual Alberto Comte).

"a gente aqui, nesse um mês de ocupações, a gente fez debate, fez aula sobre exploração de trabalho, sobre feminismo, fizemos peça de teatro, apresentações de música, são coisas que a gente não tem escola e poderia ter, mas a questão é: os alunos, professores e pais devem ter acesso e proponha atividades para a escola. Pensar em uma escola que seja da comunidade escolar, dos vizinhos, dos pais alunos, professores e não uma escola que serve apenas para ter aula [...]. Pensar que a escola é além da sala de aula e educação também é cultura" (Eudes, estudante da Escola Estadual Fernão Dias).
}

Nesses relatos de si, os jovens estudantes denunciam os sentidos estruturados nas instituições formais de ensino, principalmente no que diz respeito às práticas e valores estabelecidos hierarquicamente por meio de sua cultura escolar. Disso emerge a ideia de que toda a história de um "eu" é também a história de uma relação (BUTLER, 2018), tal suposição nos permite pensar narrativas de si no documentário como tecnologias produtoras de sujeitos reflexivos, e que os sujeitos se produzem e são produzidos no ato público da narrativa.

É possível dizer que os processos de agenciamento produzidos no documentário acionaram corpos no espaço público pela sua pluralidade relacional, o que fez grupos procurarem formas alternativas de pautarem publicamente suas agendas e reivindicações. Quer nas ruas quer nas escolas públicas de São Paulo, ecoaram vozes de ocupantes e sua rede de apoio que se uniram em pautas de luta contra a precariedade a que estavam submetidos na vida escolar e social. São jovens que se engajaram também na luta contra o machismo, o racismo, em favor dos direitos humanos e da diversidade.

\section{CONSIDERAÇões FINAIS}

Ao analisar como aspectos educativos são continuamente desdobrados na performatividade dos jovens estudantes nas ocupações das escolas públicas de São Paulo por meio da 
produção audiovisual do documentário "Acabou a paz, isso aqui vai virar o Chile! Escolas ocupadas em SP", questionou-se em que medida um filme documentário pode capturar a produção de processos educativos a partir da realidade dos corpos políticos em ocupações das escolas públicas.

Ao se constituir enquanto tecnologia produtora de memória, o documentário analisado ultrapassou o sentido de uma ferramenta de narrativização, para ser considerado um $f a z$ fazer do presente. Esse se constrói enquanto cinema de intervenção porque para além de uma comunicação de dentro para fora, ele pode ser visto como instrumento de leitura e reflexão também para o próprio interior, para aqueles que participaram de ações de ocupações ou outras atividades sociais adjacentes, por meio das narrativas de si.

Há, nesse sentido, uma dupla perspectiva de práticas educativas na narrativa do documentário: tanto os atores aprendem novas formas de falarem de si, pelas sociabilidades com reivindicação ou de reinventá-las (mas que produz uma performatividade pautada na denúncia, auto-organização, formação, diálogos e horizontalidades), como também pela sociedade mais ampla, que pode aprender a conviver e ter de aceitar as novas questões que são problematizadas.

A denúncia, auto-organização, formação, diálogos e horizontalidades são produzidos pelo movimento de política corporal, principalmente pela importância das narrativas de si que conectam os corpos, na performatividade que não é somente a produção de uma pessoa, mas também como algo encenado nos coletivos das ocupações das escolas, produção do documentário e a memória dos presentes. Afinal, as lutas por liberdades individuais se conectam no que se tem pensado como lugares de corpos atuantes e de corpos movendo-se para a mobilização social e relações de poder democráticas.

É importante, portanto, dizer que durante a observação, descrição e análise do documentário foi possível enxergar as escolas pelo movimento de política corporal dos jovens estudantes. As projeções ligadas às ações no cotidiano das ocupações produziram narrativas de si sob uma aprendizagem da democracia participativa. Essa não estava na institucionalização da representação do coletivo de forma estanque, mas sendo construída de acordo com os relatos de si de cada membro das ocupações, seja pelo movimento do corpo observador ou pelos corpos diversificados de atividades. Essas aprendizagens foram fundamentais para desenvolver formas de reivindicação e poder de se mobilizar para demandar, sempre aliadas às tecnologias/mídias alternativas.

Por sua vez, esta discussão abre uma agenda de pesquisa para continuidade na reflexão sobre o documentário "Acabou a paz, isso aqui vai virar o Chile! Escolas ocupadas em SP", principalmente na perspectiva de revisitar os corpos políticos que produziram a película, pela leitura em cine clubismos, circuitos de divulgação, reverberações nas mídias digitais, entre outros.

\section{REFERÊNCIAS}

BARCELOS, G. O documentário e o diálogo da experiência histórica na luta estudantil, entre Brasil e Chile. Cinema movimento [on-line], p. 1-21, 2017. Disponível em: https:// 
cinemovimento.files.wordpress.com/2017/06/documentc3a1rio-e-experic3aancia-histc3b3rica-estudantill.pdf. Acesso em: 4 jan. 2019.

BAZIN, A. "L'évolution du language cinématographique". In: . Qu'est-ce que le cinéma? Paris: Éditions du Cerf, 1985, p. 63-68.

BENTES, I. Estéticas insurgentes e mídia-multidão. Liinc em Revista, Rio de Janeiro, v. 10, n. 1, p. 330-343, 2014.

BRASIL. Medida Provisória Nº. 746, de 2016. Congresso Nacional, 23 set. 2016 a.

BRASIL. Proposta de Emenda à Constituição No. 241/2016. Câmara dos Deputados, 15 jun. 2016b. Disponível em: https://www.camara.leg.br/proposicoesWeb/prop_mostrarintegra;jsessionid=52C180991A59E662ACCC26A1 A206549A.proposicoesWeb2?codteor $=1497297 \&$ filename $=$ Avulso+-PEC+241/2016. Acesso em: 30 nov. 2020.

BRENEZ, N. Political Cinema Today - The New Exigencies: For a Republic of Images. Screening the past, 2013.

. Contra-ataques. In: DIDI-HUBERMAN, G. (Org.). Levantes. São Paulo: Edições Sesc, 2017.

BUTLER, J. Corpos em Aliança e a Política das Ruas. Notas Sobre Uma Teoria Performativa de Assembleia. São Paulo: Civilização Brasileira, 2018.

. Problemas de Gênero: Feminismo e Subversão da Identidade. Rio de Janeiro: Civilização Brasileira, 2003.

BUTLER, Judith; SPIVAK, Gayatri. Who sings the Nation-State? Language, Politics, Belonging. New York: Seagull, 2007.

CANEVACCI, M. Antropologia da comunicação visual. São Paulo: Brasiliense, 1990.

CORTI, A. P.; CORROCHANO, M. C.; ALVES, J. Ocupar e resistir: a insurreição dos estudantes paulistas. Educação \& Sociedade, Campinas, v. 37, n. 137, out./dez. 2016.

CROCHIK; L.; CORTI, A. P. O caráter performativo das ocupações estudantis. Anais... do VII Seminário Corpo, Gênero e Sexualidade, do III Seminário Internacional Corpo, Gênero e Sexualidade e do III Luso-Brasileiro Educação em Sexualidade, Gênero, Saúde e Sustentabilidade, Rio Grande: Ed. da FURG, 2018.

DAYRELL, J. O jovem como sujeito social. In: FÁVERO, O. (Org.). Juventude e contemporaneidade. Brasília, DF: Unesco, 2007. 
DIDI-HUBERMAN, G. (Org.). Levantes. São Paulo: Edições Sesc, 2017.

. Sobrevivência dos vagalumes. Belo Horizonte: Editora UFMG, 2011.

GEERTZ, C. A interpretação das culturas. Rio de Janeiro: LTC, 2008.

GOHN, M. da G. Vozes que gritam e vozes silenciadas na América Latina. Civitas, 15, (3), p. $491-509,2015$.

. Jovens na política na atualidade: uma nova cultura de participação. Caderno C R H, Salvador, v. 31, n. 82, p. 117-133, jan./abr. 2018.

GRANJA, V. Dziga Vertov. Lisboa: Novo Horizonte,1981.

GROPPO, L. A. Juventude: ensaios sobre sociologia e história das juventudes modernas. Rio de Janeiro: Difel, 2000.

GROPPO et al. Ocupações no Sul de Minas: autogestão, formação política e diálogo intergeracional. ETD- Educação Temática Digital, Campinas, v. 19, p. 141-164, jan./mar. 2017.

GROPPO, L. A. Novo ciclo de ações coletivas juvenis no Brasil. In: COSTA, A. A. F.; GROPPO, L. A. (Orgs.). Movimento de ocupações estudantis no Brasil. São Carlos: Pedro e João Editores, 2018, p. 85-117.

MELO, S. P.; OLIVEIRA, L. C.; SANTANA, J. F. Figurações de discentes de um programa de formação de professores no ensino superior do Brasil: traçando seus modos de ser. Revista Internacional de Educação Superior, v. 3, p. 336-356, 2017.

MELO, S. P.; SANTANA, J. F.; SANTOS, T. C. Figurações de jovens no ensino médio: traçando elementos de um jogo sociocultural. Revista comunicações, v. 25, p. 143-161, 2018.

PENAFRIA, M. Análise de Filmes - conceitos e metodologia(s). VI Congresso SOPCOM, abril de 2009. Disponível em: http://www.bocc.ubi.pt/pag/bocc-penafria-analise. pdf. Acesso em: 2 nov. 2018.

PIOLLI, E.; PEREIRA, L.; MESKO, A. S. R. A proposta de reorganização escolar do governo paulista e o movimento estudantil secundarista. Crítica Educativa (Sorocaba/SP), v. 2, n. 1, p. 21-35, jan./jun. 2016.

PRONZATO, C. "Acabou a paz, isto aqui vai virar o Chile": o diretor do melhor documentário sobre a ocupação das escolas em SP conta o que viu (Entrevista com Mauro Donato.). Diário do Centro do Mundo, 15 de fevereiro 2016. 
SÃO PAULO. Plano Estadual de Educação $\mathbf{N}^{\mathbf{0}} \mathbf{. 1 . 0 8 3 / 2 0 1 5}$. Assembleia Legislativa do Estado em 15 de junho de 2016.

SORLIN, P. Sociologie du cinéma. Paris: Aubier, 1977.

WEAKLAND, John H. Feature films as cultural documents. In: HOCKING, Paul (Org.). Principles of visual anthropology. New York: Mouton, 1995.

\section{Dados do autor:}

Samuel Pires Melo

Doutorado em Sociologia. Professor do Programa de Pós-graduação em Sociologia da Universidade Federal do Delta do Parnaíba. Parnaíba/PI-Brasil.samuelmelo@ufpi.edu.br

Submetido em: $30-12-2019$

Aceito em: 21-11-2020 